\title{
Improvisation and Communicative Agency: Contribution of an Improvisational Model to the Analysis of Communicative Agency
}

\author{
Håkon Lie \& Anne V. Nafstad
}

\begin{abstract}
Introduction: Persons with congenital deafblindness mainly communicate using the bodily tactile modality. Their expressive communication is often formulated by an authentic language that gives the persons with congenital deafblindness low readability towards the rest of the world. This can be an obstacle for the development of their communicative agency. In the present study it is investigated whether a theoretical approach to improvisation can contribute to the development of communicative agency in a person with congenital deafblindness with low readability and authentic language in a dialogical perspective.

Method: The study employs a qualitative design conducted as a dialogical single case study. Even though this research is based only on one recording of a communicative encounter between a person with deafblindness and her communication partner, it is assumed that the study can be used as a representative case study for people with low readability and authentic language.

A video of communication between a person with $\mathrm{CDB}$ and a sighted/hearing communication partner is transcribed and the transcription is analysed in three stages through 1) Conversational analysis (CA), 2) Improvisation analysis and 3) Subjectivity/intersubjectivity analysis.

Results: The Conversation analysis proved useful to identify complex turn-taking patterns in the communication. Through the improvisation model it was possible to define the degree of subjectivity/intersubjectivity in every utterance by each participant, as well as how each act was met by the other. With the improvisation model discriminations could be made between the different modalities, as vocal speech and bodily tactile acts. Regarding communicative agency, the model was useful to analyze degrees of self-expression as well as the balance of subjectivity and intersubjectivity between the participants.
\end{abstract}


Conclusion and discussion: The model of improvisation contributed to specify subjectivity/intersubjectivity and multimodality in communication, though it did not contribute to the analysis of turn-taking. The model contributed to the development of communicative agency by pointing to the open-ended outcome for each utterance as the most important factor for developing and sustaining communicative agency.

Limitations: The main limitation of this study was that the analyses were performed on only one video-clip with one dyad. Due to time constraints, a consensus check could not be carried out. Recommendations for future research is that, since this is a very innovative method in the deafblind field, replications of the study should be performed on more dyads, different dialogues and more video clips.

Recommendation for practice: The combination of conversation analysis and improvisation analyses can very well be used with focus groups of care professionals in clinical practice under supervision of a trained expert in this method of communication analyses.

\section{Keywords}

Improvisation, communicative agency, multimodality, conversation analysis, congenital deafblindness

\section{Introduction}

Persons with congenital deafblindness rarely develop facility in a cultural language that can be easily understood by others, often ascribed to the fact that because of reduced vision and hearing, they do not have access to the culture that surrounds them (Foote, 2019; Nafstad \& Rødbroe, 2015; Souriau, Rødbroe, \& Janssen, 2009). In general, persons with congenital deafblindness (henceforth: $\mathrm{CDB}$ ) communicate through different modalities (multimodal communication) with the bodily tactile modality being the most important (Janssen \& Rǿdbroe, 2007, p. 14). Multimodal communication with emphasis on the bodily tactile, can be termed atypical, with reference to "forms of social interaction where at least one of the participants has a communicative impairment which impacts the interaction"(Wilkinson, Rae, \& Rasmussen, 2020, p. 1). One can argue that congenital deafblindness is one of the most severe communicative impairments, as it is a "combined vision and hearing impairment of such severity that it is hard for the impaired senses to compensate for each other" ("Nordic definition of Deafblindness," 2016). For the purposes of this study, let us assume that persons with CDB have no cultural language, that they use the tactile sense as a main source of information and that they have individual and natural forms of communication that we can call 'authentic language'. Tetzchner and Jensen (1999) point out that Habermas (1983, 1984, 1987) conceptualizes authentic language as the actual expression of an individual's thoughts, implying that these have value for 
reaching a possible shared understanding in a conversation (von Tetzchner \& Jensen, 1999). Acceptance of the utterances of the person with CDB as authentic language and not as "mere" sounds, movements or behaviour is in line with what von Tetzchner and Jensen (1999) characterize as a truly moral professional practice (von Tetzchner \& Jensen, 1999). Even when communication partners have such a professional practice (though not all do) it is safe to assume that people with $\mathrm{CDB}$ are still subject to frequent misunderstandings and the experience of being ignored. This is due to the low readability of the authentic language of a person with $\mathrm{CDB}$, meaning that their linguistic communication is difficult to understand because it does not fulfil the expectations of the culture (Nafstad \& Rødbroe, 2015). The person with CDB needs to be resilient to be able to develop a strong communicative agency in spite of being misunderstood and ignored in communicative situations (Nafstad, 2015). Communicative agency is a dialogical concept that refers to the opportunity and ability an individual has to express their own subjective self in interaction with others, and the term is closely linked to the concept of individual voice (Linell, 2009). The foundational assumption of dialogical theory is that "our being in the world is thoroughly interdependent with the existence of others"(Linell, 2009, p. 7). We create meaning in interaction with others and the world in an interactive and contextual process (Linell, 2009). This contextual process has a temporal-spatial aspect, one that Bakthin describes as a chronotope , an interdependent and indivisible unit of time and space (Bakhtin, 2010, p. 84) ; (Marková, Zadeh, \& Zittoun, 2020), where everything that is said or done belongs uniquely to that unit, or chronotope. Bakthin says further that "(every word) provokes an answer, anticipates it and structures itself in the answer`s direction"(Bakhtin, 2010, p. 280) and we can here expand his "every word" to mean every utterance we produce and every thought we think. We are in constant dialogue with the Alter, meaning one's own inner representation of the Other (Marková, 2006). According to Markova "..the mind of the Self and the mind of the Others are interdependent in and through the sense-making and sense-creating of social realities, in interpretations of the past, experiencing the present and imagining the future" (Marková et al., 2020). Our sense-making and sense-creating of social realities, what we think of as our thinking, is therefore not an internal, autonomous process, but on the contrary, a social process where all knowledge and beliefs are creatively co-constructed with the Other (Linell, 2009, p. 12). This co-construction of meaning (intersubjectivity) is generally seen as the basis of communication, where the goal is to establish intersubjective understanding with the Other. This, however, is only one part of the dialogical process. The other part concerns how the individual struggles to establish him/herself as an agent (subjectivity), or the struggle to impose one's individual meaning onto the communication (Markova, 2008). Communication is therefore in a constant tension caused by this struggle between opposites where `a good dialogue` between persons in addition to being a peaceful search for common understanding, is also a struggle between perspectives and a constant evaluation between 
participants (Markova, 2008). Our ability to endure this tension in communication can be termed as a communicative agency (Nafstad, 2015) that lets us move freely between different perspectives and positions in a communicative situation. It should not be reductively defined as a specific communication skill or independence from others (Nafstad, 2015). However, a person with any kind of communicative impairment, will be in danger of not developing strong communicative agency because of possible asymmetry in a communicative encounter with a person with no communicative impairment. The assumption is that acts of subjectivity by the person with atypical communication, also represent a strengthening of that person's communicative agency, and further, that by being able to identify acts that reveal a person's communicative agency, small as they may be, one can build further on these acts to support the development of that person's communicative agency and thereby support the person in developing her/his individual voice (Linell, 2009, p. 114). The present study will look at communication in a dialogical perspective, with special attention to communicative agency, and investigate whether the concept of improvisation can support the development of communicative agency, especially for persons with low readability and authentic language. The concept of improvisation is broad and has multiple connotations and definitions. From its common definition as "the activity of making or doing something not planned beforehand." (Wikipedia) one can argue that improvisation is performed everywhere. From this extreme perspective, we can move to the opposite extreme and claim that improvisation is a highly specialized activity. Many musicians spend their whole life practising, and honing the art of improvisation, such as North Indian musicians playing the traditional Raga (Bailey, 1992) or Norwegian practitioners of the Harding-fiddle indulging in Villspel (wild play) (Kvifte, 2013). Other fields that highlight improvisation are drama (Johnstone, 2012), pedagogics (Moltubak, 2020) and management (Steinsholt \& Sommerro, 2006, p. 261). This is but a very small selection of fields in which you can find books and theories about improvisation. Despite this, there seem not to be many attempts to shape a definition that captures all aspects of the concept of improvisation. Rather than trying to create a clear definition MacDonald and Wilson (MacDonald \& Wilson, 2020) highlights several functional qualities that exist in all improvisation. According to them, acts of improvisation are creative, meaning they involve bringing something new into existence, and social, in the sense that improvisation can be seen as being dialogical. One always improvises with someone ( the Other). Improvisation is universally accessible, in the sense that everyone has the capacity to express themselves through improvisation; it is spontaneous, in the sense that one makes moment to moment decisions while improvising; and ambiguous, or open-ended, in the sense that any act of improvisation can be perceived or interpreted in different ways by the others. All the five qualities of creative, social, universally accessible, spontaneous, and ambiguous must be present to identify something as an act of improvisation (MacDonald \& Wilson, 2020, pp. 26-30). The term is still very open, but it is the 
combination of these five qualities that makes improvisation unique. Improvisation must be understood as a communicative, open-ended, and therefore dialogical process, where every decision made in the here and now is a responsive act towards the Other, as when two persons create something new together in everyday speech (Nachmanovitch, 1990, p. 95). During a study of free group improvisation based on video-recordings of different musicians performing free improvisation together and interviews of the musicians explaining their strategies and choices during the improvisation- (Wilson \& MacDonald, 2016), researchers developed a model that represents the choice-making process during group musical improvisation: "an open-ended iterative cycle where all choices lead to a subsequent reconsideration" (Wilson \& MacDonald, 2016, p. 1035). According to the model the first choice to make is whether to maintain what you are doing (while improvising) or to change. If you opt to change you either initiate something new or respond to something. A response can be either adopting, augmenting, or contrasting the message of the others.

Figure 1: Model for the process of individual choice during group musical improvisation (Wilson \& MacDonald, 2016)

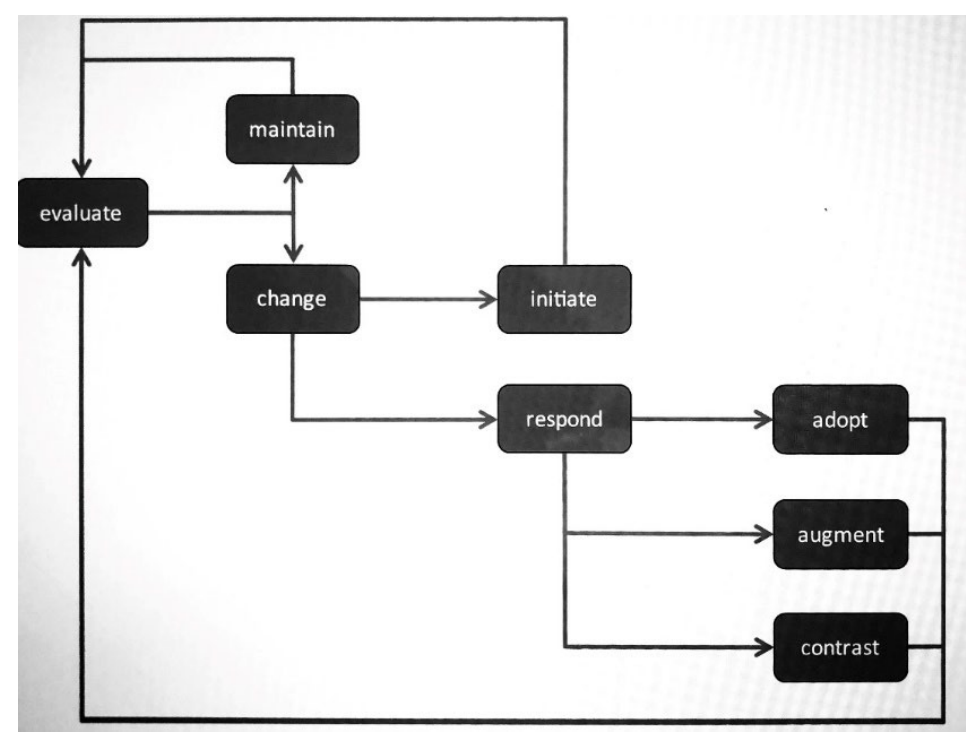

Contrasting the utterance of another is described as providing a contribution that accompanies those of others, but does not share their characteristics (Wilson \& MacDonald, 2016, p. 1035). This description seems lacking in that a model of decision-making in groupimprovisation also needs to represent disagreement and opposition. In this analysis, to "contrast" is defined as "to oppose or disagree with the former utterance". Even though this is a model of individual choice, it can clearly be seen in a dialogical perspective because it is based on constant interaction with and response to the Other. As Bakhtin remarks, "everything we say and do is a response to something" (Linell, 2009, p. 186). The authors argue 
that "live improvisation of music by two or more individuals is a creative activity that unfolds in real time within a social group yet does not depend on verbal or visual communication. As such it is a unique phenomenon"(Wilson \& MacDonald, 2016, p. 1029). Further, they claim that " despite parallels drawn with conversational language use, contributions to improvised (music) are predominantly simultaneous rather than turn-based" (Wilson \& MacDonald, 2016, p. 1030). The present study explores whether multimodal communication between a person with $\mathrm{CDB}$ and a seeing/hearing communication partner can have the same qualities as live improvisation of music by two or more individuals. The study further explores if, as opposed to turn-taking patterns in verbal conversation in which turns are predominately taken one after the other, multimodal communication or interaction can be structurally quite different. In an atypical multimodal interaction sequence, one might observe several modalities at play simultaneously, so that even if we cannot say that contributions to multimodal interaction are predominately simultaneous rather than turn-based, the turns might at the least be much more complex to distinguish from each other and/or be perceived as being out of turn. To examine in-depth the sequential organisation of turn taking in an improvised, atypical multimodal interaction sequence, the ethnomethodology of conversation analysis (CA) can be a useful approach that offers a systematic way of gathering, transcribing and analysing social interaction (Skovholt, Landmark, Sikveland, Solem, \& Skovholt, 2021). CA is built on the assumption that all conversation is sequentially organised, meaning that social actions occur one after the other (Stivers, 2013, p. 191). Social actions such as asking, telling, inviting etc. along with their sequential answers form adjacency pairs (Sacks, 1966). These adjacency pairs are basic units of sequence-construction in CA, in which each utterance has a reflexive relationship with that which has come before and that which follows (Schegloff, 2007). Normal turn-taking in a conversation or interaction is based on adjacency pairs. Adjacency pairs can stand alone as two-part sequences, but they can also be expanded by either pre-expansion, insert-expansion or post-expansion (Stivers, 2013, pp. 159-163) in (Skovholt et al., 2021, pp. 42-45). According to the next turn proof-procedure (Skovholt et al., 2021, p. 80), an utterance must be interpreted through its next turn to see how the participants themselves treat the utterance in the sequential context (Peräkylä, 2011). Another form of sequential organisation in CA is storytelling (Schegloff, 2007), where the teller sets aside normal turn-taking rules to bring the story to completion (Mandelbaum, 2013). A third important concept from CA is that of repair, where attention is needed to address trouble in speaking, hearing or understanding (Kitzinger, 2012). Repair ensures that "the interaction does not freeze in its place when trouble arises, that intersubjectivity is maintained or restored, and that the turn and sequence and activity can progress to possible completion" (Schegloff, 2007). A basic difference between CA and the improvisation-based decisionmaking model, is that the former is structural, focusing on the organization of turns, 
sequences, and actions, while the latter is psychological, based on participants choices in a dialogical process with the Other (Markova, 2008)

\section{Problem statement}

The present study will look at communication in a dialogical perspective, with special attention to communicative agency, and investigate whether the model of improvisation, as developed by Wilson and MacDonald (MacDonald \& Wilson, 2020, p. 71) can contribute to, or support the development of communicative agency, especially for a person with CDB, with low readability and authentic language. To be able to formulate starting points for better educational support in practice, one must know how aspects of improvisation can contribute to the understanding of communicative agency. Communicative agency will be analysed in terms of the important concepts of turn-taking patterns, dynamics of subjectivity and intersubjectivity and multimodal interaction.

The similarities between free improvisation and multimodal interaction lead us to the main research question:

How can an improvisation model contribute to the analysis of communicative agency of a person with congenital deafblindness?

(1) Sub questions:

To what extent can this improvisation model contribute to the analysis of

1. turn-taking patterns?

2. the dialogical dynamics of subjectivity/intersubjectivity?

3. different modalities in multimodal interaction.?

This research has general social relevance for the field of deafblindness, atypical communication and special education in general. Improvisation theory, as outlined in this study, can add new perspectives to present understanding of communicative agency, and therefore new perspectives about why persons with low readability and their own authentic language, stay in interaction, despite a lack of shared understanding with their communication partners. In addition, the study sheds light on new competencies in people with atypical communication. The results of the study may inspire other studies so that greater knowledge is progressively developed that can capture more of the multimodality and dialogicality that characterizes atypical interaction. 


\section{Research design}

This study is a qualitative study performed as a dialogical single case study (Marková et al., 2020). According to dialogical theory, the uniqueness of the Self-Other interdependence makes it necessary to treat each case as a single instance (Markova, 2017). The study is based on a videorecording of two persons in interaction, one with CDB and one seeing/hearing communication partner. The videorecording has been transcribed and analysed, with the aim of answering the research-questions. A dialogical single case study is the study of a single case in which it is treated as whole rather than in terms of its independent elements. This whole is viewed through an open-ended perspective and the case study involves researching a phenomenon directly from real life (Morgan, 2012). As a dialogical single case study rather than merely a single case study, ethical and dynamic aspects must also be included. In a dialogic perspective, Self and Others experience each other as human beings, and therefore evaluate, interpret, and react to one another, as "a dialogical single case study (...) involves ethical and dynamic interdependencies between Self-Other(s)" (Marková et al., 2020, p. 6). Different research methods can be used in case studies, but the dialogical case study emphasises the collection and later transcription and analysis of video-ethnographic data.The videorecording selected for study will then be studied numerous times with the aim of producing a transcript of individual sequences. Vocal speech and signing will be transcribed according to the conventions developed by Gail Jefferson (Jefferson, 2004) whereas the multimodal details will be transcribed according to conventions developed by Lorenza Mondada (Mondada, 2007). Spoken Norwegian will be translated into English by the researcher. A structured analysis of the transcript will be performed (Davidsen \& Kjær, 2018), applying: 1) The theory of conversation analysis (CA) (Sidnell, 2013), 2) Improvisation theory (Wilson \& MacDonald, 2016), and 3) The dialogic theory of the concepts subjectivity/intersubjectivity and communicative agency (Linell, 2009; Marková, 2016; Nafstad,

\section{Selection of video-data}

The video camera is an effective tool for the documentation of communicative resources (Due, 2017, p. 25) in multimodal communication. According to Mondada, videorecording "attempts to preserve the fluidity and temporality of the events, but also constitutes a reification of these events in a limited record" (Mondada, 2013, p. 42). It was assumed that improvisation can be found in all dialogical interaction, therefore, improvisation as described in the introduction of this study did not serve as a criterion for selection of the specific videorecording. Any recording showing activity and engagement of the participants under motivating conditions (Nafstad \& Rødbroe, 2015, p. 188) was of 
interest. The criteria described by Nafstad and Rødbroe (2015) were used to identify a videorecording worthy of further analysis: a) activity, b) reciprocity, c) factors that extend this reciprocity, d) increasing interactional complexity, and e) stability. A video fragment of 16 minutes of interaction between one person with CDB and her communication partner was identified. The researcher located this video with the help of a former colleague of the communication partner. A sequence lasting 51 seconds was selected by the researcher for further study in accordance with the criterion of change in the interaction (Due, 2017, p. 123). Within this sequence, a point was identified that appeared to represent change, transition or a break that altered the theme of the interaction (Jefferson, 1984). Many other video sequences of the same quality were available to the researcher, but a choice had to be made based on the aforementioned criteria (Nafstad \& Rødbroe, 2015). This video was not chosen for its uniqueness, but rather for its representation of a normal multimodal communicative encounter between a person with CDB and a person with sight and vision. Analysis of a higher number of videos was considered, to improve reliability of the results (Flick, 2018), but due to time constrictions, the researcher chose a detailed analysis of the one video.

\section{Participants}

The participants of the videorecording are Ina, a young woman with CDB, and Tone, her sighted/hearing communication partner. Both names are fictitious, and for reasons of anonymity no exact ages will be given, but the women with $\mathrm{CDB}$ is in her twenties. Ina has some residual sight and hearing, but it is difficult for her carers to be certain of how she profits from these. She can see movement and light/shadow, but probably not visual detail. Her hearing is complex in the sense that she seems to register most sounds but does not appear to be able to decipher them. She communicates with sounds, more specifically with songs, a few Norwegian signs in the tactile modality, gestures, and movement. Her use of signs can be seen as over-extensions, or "the use of a word for a broader range of referents than is conventional in adult usage" (Anglin, 1977; Rescorla, 1980). Because she uses few signs, we must assume that these have a meaning for her that goes beyond their formal, cultural meaning. The sign for 'Parachute', used in the transcript, is such a sign. Ina`s relation to song is special, as she knows the melodies of many Norwegian songs. She appears to use them in a way that is meaningful to her, where the lyrics fit the situation she is in. Tone communicates with Ina using tactile signing, spoken Norwegian as well as singing Ina`s songs. She has worked as a carer/teacher for more than ten years and have been trained in interaction/communication with persons with $\mathrm{CDB}$ through many training courses and extensive work-experience. It is therefore probable that she is familiar with the term communicative agency, but she has no specific knowledge of the theory of improvisation. 


\section{Informed consent and ethical considerations}

Ethical considerations includes respect by the researcher for the participants and commitment to their rights; both form the basis of ethical conduct in social research (Robson \& McCartan, 2016, p. 208). On a personal microlevel (Brinkmann, 2015, pp. 463-478) participants` rights have been secured by ensuring that their participation is voluntary. With respect to the professional communication partner this means full transparency regarding the intention of the research and signed, written consent to participate. For the person with CDB, this is not possible because of limited access to understanding the full scope of the research. Therefore, a written consent was obtained from her legal guardian (in this case, a parent). Obtaining written consent from a legal guardian cannot be considered equal to informed consent from the actual person, however "these are trade-offs that can only be made for a specific study and not generally" (Flick, 2020, p. 62) The research did not in any way interfere with the normal life of the participants on an emotional or any other level, and therefore did not cause harm to the participants (Flick, 2020, p. 65). The data was further anonymized by changing all names, and by scrambling the pictures used in the transcript. The videorecording was stored on a computer with no internet-connection, where only the researcher has access through

a

password

(Flick,

2020 ,

p.

$63)$.

\section{Description of the video}

The sequence chosen for analysis is of a normal, everyday situation, where Tone's intention is to fetch the vacuum cleaner with Ina so that they can clean Ina`s apartment. Ina`s intention might be something different. The vacuum cleaner is in the corridor outside, so they walk together in the direction of it. The recording is from several years prior to this research, so no action in the sequence was affected through being part of the research. Both participants, however, are aware of the camera and the person behind it (Tone`s colleague who is following them with a hand-held camera). Earlier in the full video, Ina is seen being presented to the person filming, and one must assume that Tone is the one who initiated the situation in deciding what to do in front of the camera. The question of reliability is not so much about whether they are aware of the camera, but more whether their behaviour is affected by it (Due, 2017, p. 74). In this chosen sequence, both Ina and Tone are preoccupied with one other and show no sign of "acting" in front of the camera. For Tone in particular, who has an intention in filming, one must assume that part of her attention is directed towards an "audience", as in the dialogical Other (Marková, 2006). 


\section{Transcription of video data}

Transcription of the videorecording followed the conventions of Jefferson`s transcription symbols (Jefferson, 2004) as a basic structure, however, as these symbols are very speech oriented, more conventions were needed for the embodied expressions. Lorenza Mondada based her transcription conventions (Mondada, 2007) on Jefferson`s but added possibilities for transcription of all multimodal actions by using different symbols to designate different actions carried out by the participants. These symbols are randomly chosen by the researcher. Some examples:

\section{$\pm \pm \quad$ designates Tone`s body movement \\ $¥ ¥$ designates Ina`s vocalisation}

In the first example, Tones body-movement occurs between the two signs of \pm , they designate the movements. This transcript focuses specifically on attention/directedness expressed as gaze and attention/directedness expressed in hand positions through tactile hand positions, so symbols are chosen accordingly. Some examples:

lp listening position, using both hands

$\dagger \dagger$ designates Tone`s gaze/direction of attention

Still photos from the video are also used in the transcript to increase readability (Broth \& Keevallik, 2020, p. 63). Transcript and transcript keys are included as appendices to the study (Lie, 2021).

\section{Data analysis in three stages}

Analysis of the transcript was performed of its detail and accuracy. This was carried out in three stages:

\section{Stage 1 Conversation Analysis}

First stage was to organise the transcript sequentially through CA (Sidnell, 2013) to look at "multimodality in relations to the organization of turns, sequences and actions, in order to understand how action is made intersubjectively accountable and intelligible" (Mondada, 2018). Based on the theory of CA, analysis focused on organisation of the social actions in the videorecording into adjacency pairs (Sacks, 1966; Skovholt et al., 2021, p. 40). Adjacency pairs consists of a first-pair part action (FP) and a second-pair part action (SP) (Stivers, 2013, p. 192) as basic components. The adjacency pair sequence may be expanded but can also function alone (Stivers, 2013, p. 192). In traditional speech-oriented CA, adjacency pairs consist of 
spoken parts. However, as this was a multimodal CA analysis, it was important to note that multimodality includes linguistic and embodied resources that must be treated in principle in the same way, without supposing that one is more important than any other (Mondada, 2018). The linguistic resources in this analysis consisted of spoken Norwegian, song, and vocal utterances, and the embodied resources consisted of a few signs from Norwegian Sign Language, gestures, pointing, gaze, spatial movement, and the hand positions of listening and speaking hands. Treating all these resources with equal importance provides access to a complex communicative situation in which the different resources are used by both participants in an overlapping and simultaneous flow that makes it more challenging to identify the exact turn-taking in the conversation. Further, as this analysis shows, this kind of multimodal conversation expands the notion of adjacency pairs, in the sense that these are not necessarily adjacent nor in an order such that particular first-pair parts precede secondpair parts (Stivers, 2013, p. 192). This does not mean that SP precedes the FP, but rather that the analysis was opened to the possibility that the SP was concluded before the FP is finished, and also that new adjacency pairs were introduced before conclusion of prior pairs.

\section{Stage 2 Improvisation analysis}

After being sequentially organized, the transcript was analysed using the model of individual choice during group improvisation developed by Wilson and MacDonald (2016), in combination with their definition of improvisation as creative, social, universally accessible, spontaneous and ambiguous (MacDonald \& Wilson, 2020, pp. 26-30). This analysis built on the initial CA analysis, in the sense that, through CA, the sequential structure of the interaction transcribed from the videorecording was made visible. Further, analysis was made of every linguistic and embodied utterance and action with reference to the choices participants made in a spatial and temporal context. From a CA perspective, the main adjacency pair in this model is initiate-respond. One either initiates something new or responds to the other person`s initiation. Response is split into three variations: adopting, augmenting, or contrasting the message of the Other. The model also contains the option of maintaining, that is, keeping the status quo. In a dialogical perspective, maintaining, in the sense of doing nothing, is not really an option as every action is part of a constant dialogue with the Other; however, in a CA perspective one can argue that being the recipient of storytelling by the Other in which normal turn-taking rules are put aside is a way of maintaining the situation. 
Figure 2: Model for the process of individual choice during group musical improvisation (Wilson \& MacDonald, 2016)

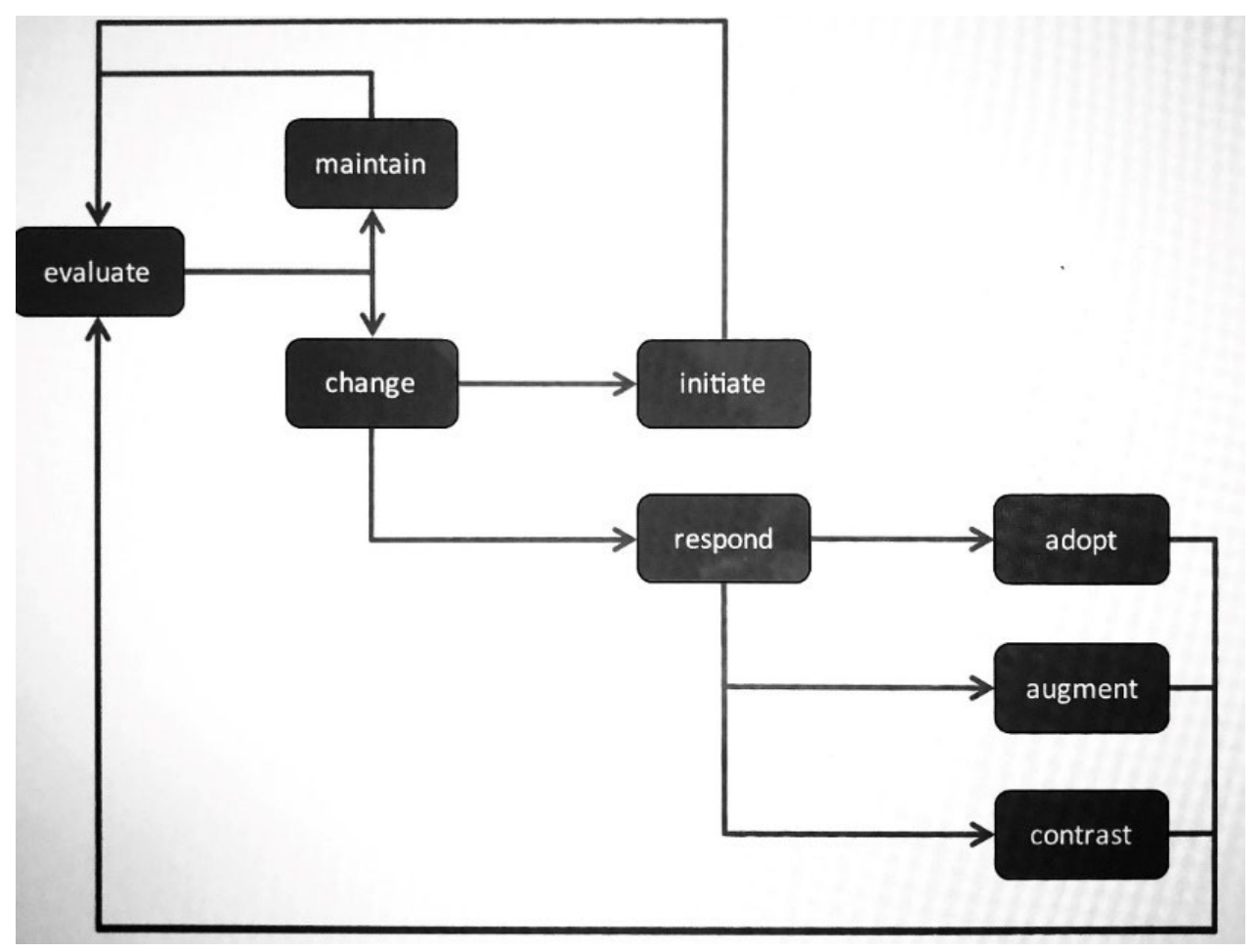

\section{Stage 3 Subjectivity/Intersubjectivity analysis}

All these decision alternatives can also be viewed from a more dialogical perspective, from which every utterance can be seen in a temporal and spatial context to be expressing greater or lesser subjectivity or intersubjectivity. The table below depicts the choices Change, Initiate and Contrast as acts leaning towards subjectivity and the choices Maintain, Respond and Adopt represents acts leaning towards intersubjectivity. Intersubjectivity is here viewed in terms of the aim of establishing a common understanding with the Other and subjectivity as the drive to impose one`s individual meaning onto the communication (Markova, 2008). Augment is placed in the middle because it represents the gliding of intersubjectivity originating in a common understanding with the Other to subjectivity in the sense of the addition of a speaker`s individual meaning in the choice of augmentation of the utterance of the Other: 


\begin{tabular}{|c|c|c|}
\hline \multicolumn{2}{|l|}{ Subjectivity } & \multicolumn{2}{l|}{ Intersubjectivity } \\
\hline \multicolumn{2}{|c|}{ Change } & \multicolumn{2}{c|}{ Maintain } \\
\hline \multicolumn{2}{|c|}{ Initiate } & \multicolumn{2}{c|}{ Respond } \\
\hline Contrast & Augment & Adopt \\
\hline
\end{tabular}

Following analysis of the transcript sequentially through the improvisational decision model and through the dialogical dynamics of subjectivity-intersubjectivity, the sub questions will be answered and finally the main research question of how an improvisation model can contribute to the analysis of communicative agency of a person with congenital deafblindness can be answered.

\section{Results}

These analyses are based on the transcript, rather than on the actual videorecording. Some parts of the transcript are presented as examples in the text, but the full transcript with the relevant transcription conventions is enclosed in the Appendix of the master thesis "Improvisation and communicative agency" (Lie, 2021).

\section{Conversation analysis}

This first adjacency pair is straightforward. Ina`s laugh-like utterance $(1,1)$ in combination with her looking down $(1,3)$ and waving her hands $(1,4)$ is the FP and Tone looking at Ina $(1,6)$ and affirming her utterance by saying "Yes" (02) is the SP of the adjacency pair. This is straightforward in the sense that Tone is responding to Ina`s vocal utterance without necessarily knowing the meaning of the utterance but treating it as an action and a communicative utterance that requires a reply. 
Extract 1

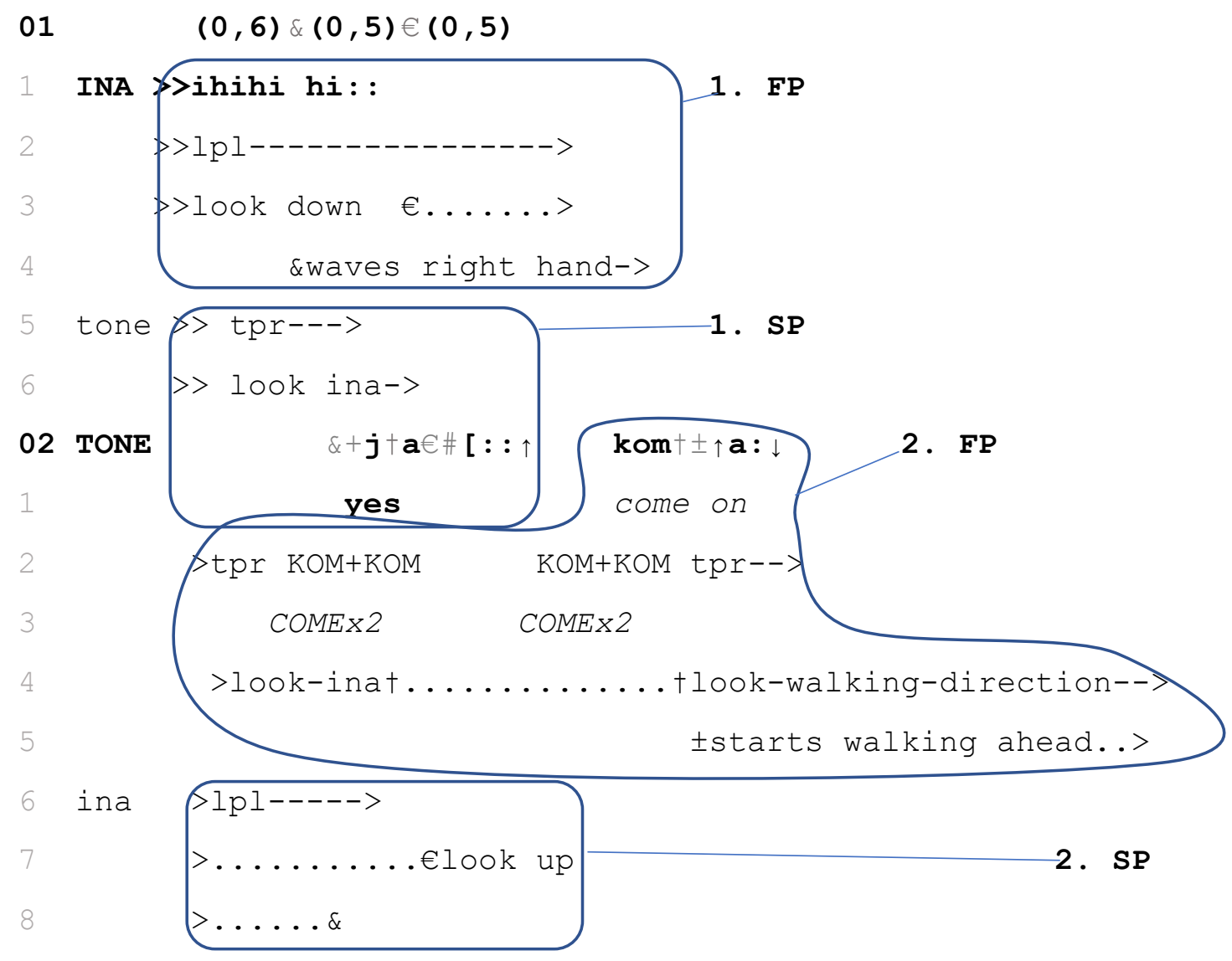

03 INA

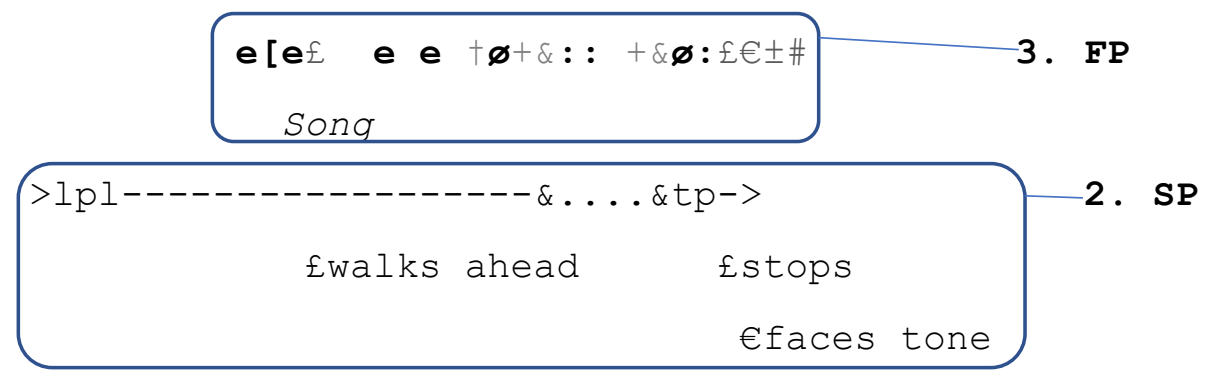

In the continuation of line 2, where Tone says, "come on", it is already obvious that their multimodal communication appears as a complex simultaneity rather than sequential interaction. It seems at first that Ina reacts when Tone says "come on", making this the FP of the next adjacency pair: an invitation awaiting either acceptance or a declination (Stivers, 2013, p. 192). However, the invitation begins earlier. When Tone says "yes" (2), and thereby concludes the first adjacency pair with its SP, she is at the exact same time or even before this beginning the next adjacency pair by signing "come" three times $(2,2)$ before she speaks the word vocally, and then signs the word for the fourth time after her vocal "come on" (2). Ina`s reply in the form of a SP begins when she stops waving her hands $(2,8)$ and looks up $(2,7)$. She then starts walking $(3,3)$ in the same direction from which Tone is beckoning her, a clear 
indication that she has accepted the invitation signed to her by Tone. Ina`s reaction, or action in the SP of the second adjacency pair, occurs before Tone speaks, indicating that the SP is over before the FP is completed. The third adjacency pair begins with Ina`s song-like utterance (3), and this is a FP of the third adjacency pair precisely because Tone perceives it as a FP utterance and sings back the same line later (4). Ina`s song begins exactly as Tone ends her SP in the first adjacency pair by saying "yes" (2), and continues all through the second adjacency pair, so that there are three adjacency pairs in use simultaneously. As in the former example we see Tone beginning to speak to Ina (17) vocally, as she holds her hands in a talking position following the rhythm of Ina`s song $(17,2)$, before stopping in front of Ina $(17,3)$. Ina keeps on singing her song $(17,4)$, and as in several previous adjacency pairs, Ina finishes her SP before Tone has completed her FP of the adjacency pair. Tone keeps on trying to persuade Ina (18) by explaining how she is going to help her perform her task (fetching the vacuum cleaner). At the same time, she blocks Ina`s path by standing in front of her $(17,3)$ and holds her own hands in speaking position $(17,2)$, thereby executing a certain amount of control over Ina`s movements, before she turns and walks back $(18,3)$ leading Ina by maintaining her right hand in speaking position $(18,2)$. Ina stops singing and utters two sounds $(18,4)$ in her SP. She moves from both hands in listening position $(17,6)$ to only her left hand in listening position $(18,5)$, in a short delay before turning and walking $(18,6)$ with Tone. From the way in which Ina stops singing before turning around hesitantly to walk back after having been stopped when she walked in the other direction (away from the vacuum cleaner), one must assume that she has given in to Tones will.

\section{Improvisation}

The second part of this analysis is based on the model for the process of individual choice during group musical improvisation (Wilson \& MacDonald, 2016, p. 1035). In this first example Tone initiates her turn using tactile signs $(2,2)$ with her right hand, asking Ina to follow her. This happens simultaneously with Tone maintaining the former theme of sequence 1 . Here we can see that Tone maintains the previous theme verbally while initiating a new theme with tactile signs at the same time. Ina begins to respond to Tone`s request by evaluating $(2,6)$ the situation, keeping her left hand in a listening position as she gradually looks up and equally gradually stills her hand movement. Ina is here in a thinking position. She then decides to initiate (3) her own theme, the melody of a song. Very shortly afterwards she also responds to Tone`s request by adopting her theme of movement by starting to walk $(3,3)$. Tone then repeats her message vocally by saying "come on" (2), which is her way of maintaining and staying within the same theme. 
Extract 2

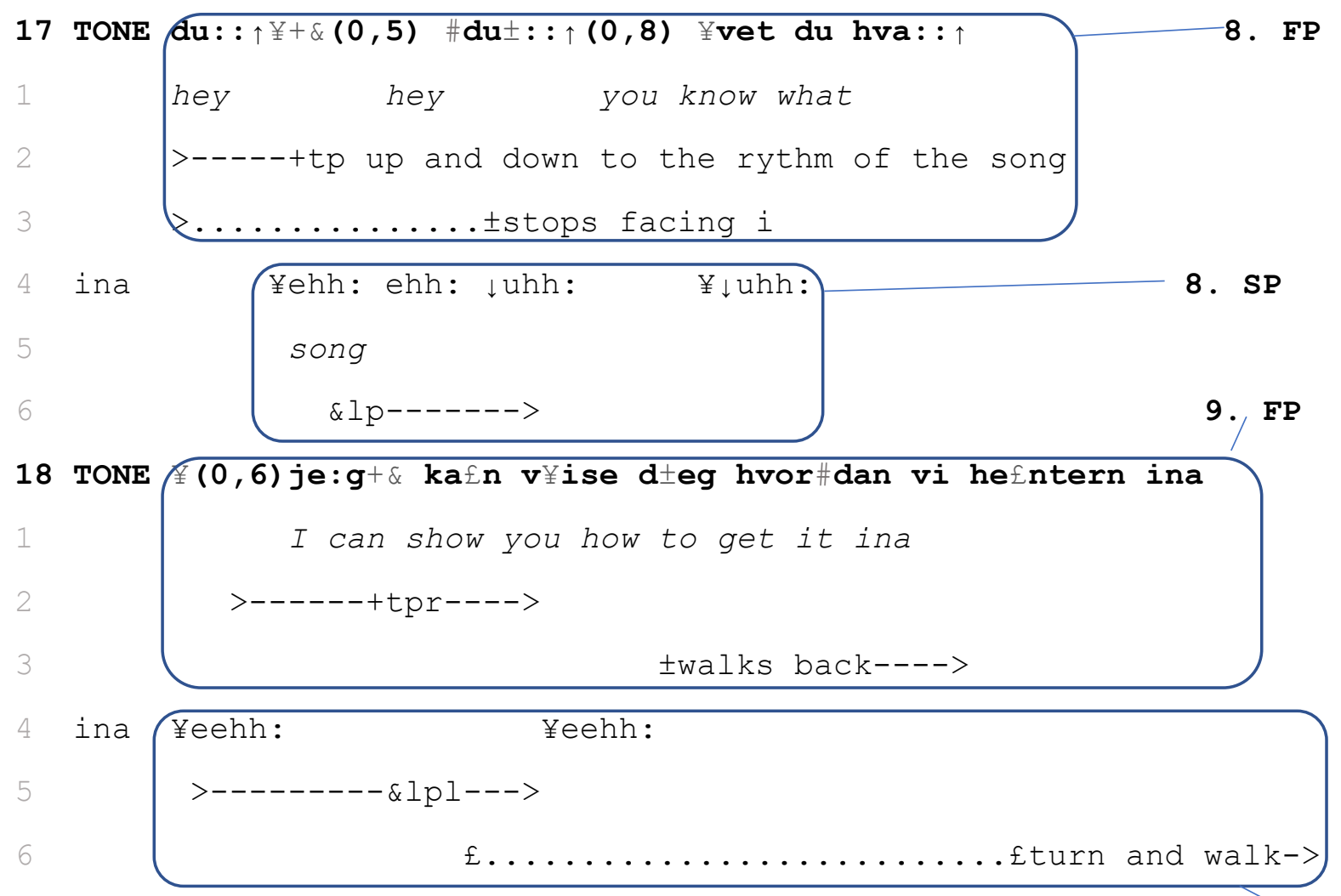

9. SP

This utterance from Tone is not responded to by Ina, though Tone responds to Ina in a bodily manner in the middle of her own verbal utterance. Tone starts to walk $(2,5)$ directly after saying "come..."(2). This is an embodied response to Ina, who begins to walk in line behind her $(3,3)$. Tone`s response is not only through her adoption of Ina`s theme of "walking", but her augmentation of it by both walking $(2,5)$ and looking in the walking-direction $(2,4)$. Now they are both walking together until Tone initiates a new theme when she turns to face Ina $(3,6)$ and shifts her hand position from speaking to listening $(3,5)$. Ina responds immediately by changing her hands from listening to speaking position $(3,2)$, then she augments Tone`s theme by stopping $(3,3)$, before she finally faces Tone $(3,4)$. Tone then stops $(3,7)$. Lines 3 and 3,3 , provide good examples of how all the different utterances - linguistic, embodied and vocalized - must be treated as choices made in the here-and-now. One could justifiably treat Ina`s walking ahead $(3,3)$ and singing $(3)$ as one coherent utterance. However, the two utterances, one embodied and one vocalized, are responded to in different manners and at different moments in time. Ina`s embodied utterance (walks ahead, line 3,3 ) is responded to by Tone in line 2,5 (starts walking ahead), whereas her vocalized utterance, the song (3) is not responded to until line 4 (Lie, 2021, p. 65), when Tone sings the same musical phrase back to Ina. 
Extract 3



According to "the next turn proof-procedure", that states that an utterance must be interpreted through its next turn to see how the participants themselves treat the utterance in the sequential context, splitting lines 3 and 3,3 into two different utterances, or choises, seem most appropiate. In line 15 we see a rapid exchange between Tones initiating and Ina`s contrasting. The level of conflict, or the potential for it, is increasing. Tone initiates by saying "come on" verbally (15) as she simultaneously reaches her right hand back $(15,2)$ to get into physical contact with Ina. Ina contrasts Tone`s utterance by turning around $(15,5)$, a movement that Tone contrasts again by saying "join me" (15), as she continues to reach toward Ina. Ina contrasts this once more (her third sequential contrast) by pushing Tone`s hands away $(15,4)$. Then Tone reduces the level of potential conflict by adopting (somewhat delayed) Ina`s movement and turns around to walk back $(15,3)$. This causes Ina to initiate a new theme (actually, an old theme repeated from earlier) raising both hands to start expressing the word "Parachute", but Tone contrasts this immediately by reaching out $(15,2)$ for Ina again. 
This is contrasted by Ina $(16+16,2)$, who signs "Parachute" and begins to sing, but again she is met with Tone`s contrasting message of raising both her hands towards Ina $(16,4)$, turning around $(16,5)$ and lifting both hands into speaking position $(16,4)$. To accomplish this, Tone must stand directly in front of Ina, thus effectively stopping her dead in her tracks. Ina then responds by adopting Tone`s themes of hand-positions and stopping. Line 17 begins with a good example of how an utterance can be viewed either as an initiation of something new or as a contrast to a former utterance. It is possible to read lines $17-17,3$ as a continuation of Tone`s contrast from line 16,4-5, since the embodied movement follows directly from lines 16,4-17,2 when Tone has both hands in speaking position on top of Ina`s hands, then proceeds to follow the rythm of her song.

Extract 4



16 $\varepsilon(0,1) ¥+(0,5)(1,0) \quad ¥ \varepsilon(0,2) \pm(0,3)+£(0,5) £$




In this reading, the movement follows directly from line 16,5 through to 17,3 when Tone turns and gradually comes to a full stop in front of Ina. This move is likely to raise the level of conflict because it expands on the last uttered contrast which was already the third in a sequence of contrasts. It could also imply that Tone disregards Ina`s adaptation in line 16,2-3, an utterance that can be seen as an attempt to reduce the level of conflict. If, however, we perceive line 1717,3 as an attempt to initiate something new, Tone`s vocal utterance, "Hey, hey, you know what?" (17) in combination with her hand movements can be viewed as a response to Ina`s adoption in line 16,2-3. This move could temporarily lower the level of conflict. Tone`s attempt to initiate something new with her question as she continues to follow Ina`s rhythmical hand movements, thereby showing acknowledgement of her theme of the song, could be seen to raise the level of understanding between them, except for one thing: Tone remains standing in Ina`s way, directly in front of her.

Extract 5

INITIATE

17 TONE
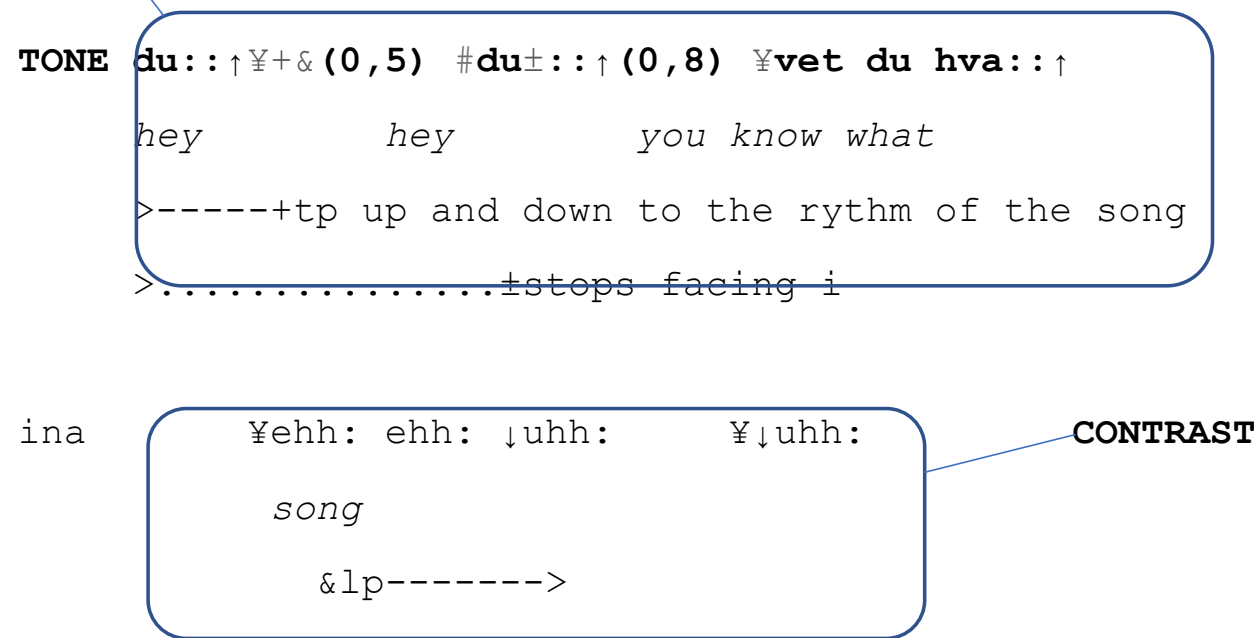

CONTRAST

18 TONE

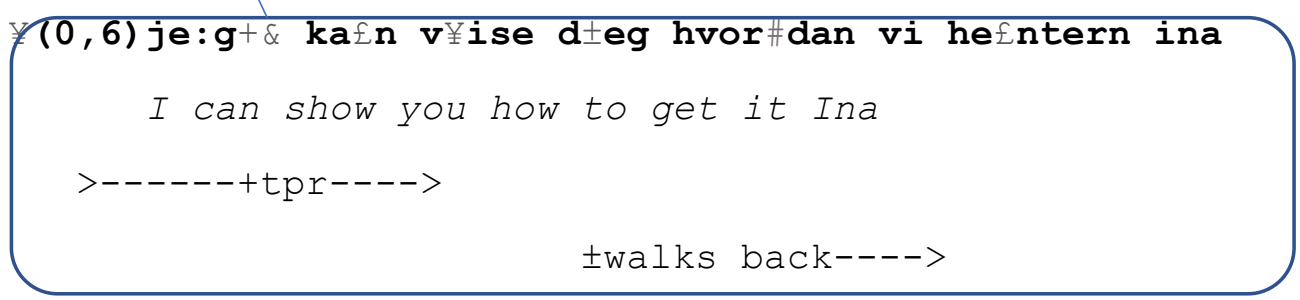

ina

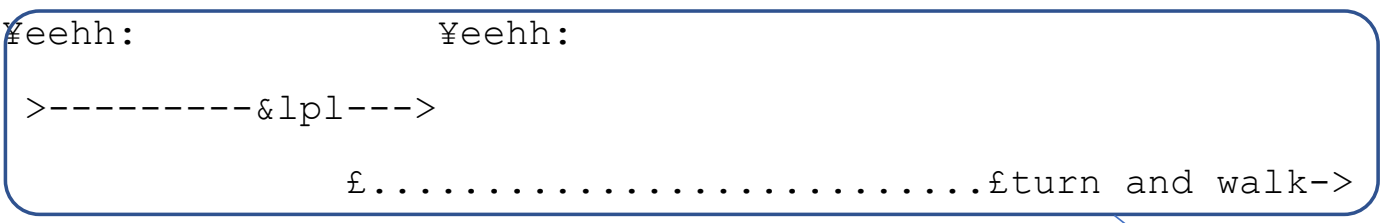


Ina has been trying to physically escape the situation for a while, but her opportunity at this point to continue with this is strongly restricted by Tone. When Ina continues to contrast Tone $(17,4)$ by sticking to her own theme (her song) instead of showing any interest in Tone`s question, singing is all she is able to do. Her movement, the driving force throughout the whole sequence, has been stopped. Tone could then be seen as contrasting Ina`s song (18), by sticking to her own theme of "moving back towards the vacuum cleaner", when she tells her vocally, "I can show you how to get it, Ina". This can be seen as an attempt to help and support her (show you), but in combination with leading Ina with her right hand in speaking position, as she starts to walk back, it can also be perceived by Ina as a final argument for turning back towards the vacuum cleaner.

Ina adopts Tone`s theme $(18,4)$, as she allows herself to be led, her left hand on top of Tone`s right hand, to turn and walk back. Her sounds are now just sounds; the singing has stopped.

Throughout this sequence, the five qualities of improvisation are constantly present. The improvised communication is creative, social, universally accessible and spontaneous. The last quality however, that of being ambiguous, or open-ended, is not necessarily present all the time. When an utterance is contrasted, the dialogue remains open-ended if the contrast is responded to with adoption or augmentation, or by initiation of something new into the dialogue. Trouble begins if a contrast is met with another contrast, and this is even so if more contrasts follow the first sequentially, as in line 15 where we have three acts of contrast in a row. This decreases the openness of the dialogue, and there is not any longer, or at least less, ambiguity in the interaction.

\section{Subjectivity/intersubjectivity}

\begin{tabular}{|c|c|c|}
\hline \multicolumn{2}{|l|}{ Subjectivity } & \multicolumn{2}{|c|}{ Intersubjectivity } \\
\hline \multicolumn{2}{|c|}{ Change } & \multicolumn{2}{c|}{ Maintain } \\
\hline Initiate & \multicolumn{2}{c|}{ Respond } \\
\hline Contrast & Augment & Adopt \\
\hline
\end{tabular}

The table introduced in the Method chapter shows the choices of Change, Initiate and Contrast as acts leaning towards subjectivity, and the choices of Maintain, Respond and Adopt as acts leaning towards intersubjectivity. The choice of Augment is placed in the middle, making it possible to count the number of acts leaning towards each mode for both participants during the 51-second duration of the sequence, and thereby provide a measure of the balance between these modes in the interaction. The choices of Change and Respond 
are not part of this second table as they are not the final choice. In the model, Change is followed by either Initiate or Respond, and Respond is followed by Adopt, Augment or Contrast. As these two tables show, acts leaning towards subjectivity appear more frequent than acts leaning towards intersubjectivity. This applies to both participants, even though the extent of the difference between how often the two modes appear is higher for Ina than for Tone. We see that Ina has more than double as many acts of subjectivity than acts of intersubjectivity (14/6) while for Tone the number is more balanced (15/11). Both participants use the acts of initiate and contrast (both leaning towards subjectivity) most frequent in this sequence. This might suggest that the sequence is characterised by a high level of disagreement or conflict.

\begin{tabular}{|l|l|l|}
\hline Intersubjectivity & I & T \\
\hline Maintain & 2 & 4 \\
\hline Adopt & 3 & 4 \\
\hline Augment & 1 & 3 \\
\hline & 6 & 11 \\
\hline
\end{tabular}

\begin{tabular}{|l|l|l|}
\hline Subjectivity & I & T \\
\hline Initiate & 7 & 7 \\
\hline Contrast & 6 & 5 \\
\hline Augment & 1 & 3 \\
\hline & 14 & 15 \\
\hline
\end{tabular}

However, the full sequence starts with a balanced flow of acts of subjectivity immediately followed by acts of intersubjectivity. In lines 1-8 of the transcript, there are 8 acts of initiating something new, 5 by Ina and 3 by Tone, and they are all followed by acts of maintaining, augmenting, or adopting the themes that are being presented. When the acts of subjectivity (here, to initiate) are met by acts of intersubjectivity (here, to maintain, adopt or augment), the effort is made by each to establish a common understanding.

In lines 9-11, however, this pattern changes somewhat. This sequence was analysed during the second phase of the analysis and the main analytical point is that when Ina meets Tone`s initiation of a new theme by contrasting it, the possibility of conflict is very present. When Tone meets Ina`s contrast by adopting it however, the conflict disappears simply because it is not perceived as conflict by either of the participants. One can say likewise say that Tones act of subjectivity $(9-9,3)$ is met by Ina`s even stronger act of subjectivity $(9,4-10,2)$ and that this indicates the possibility of disagreement, conflict, or at least an increased tension between the two, though when Ina`s act of subjectivity is met by Tone`s act of intersubjectivity (11-11,3), the conflict or tension decreases. By choosing an act of intersubjectivity as a reply to Ina`s act of subjectivity and thereby decreasing the tension, Tone facilitates the development of Ina`s communicative agency by supporting her ability to endure the tension between her striving simultaneously for both subjectivity and intersubjectivity. 
Extract 6

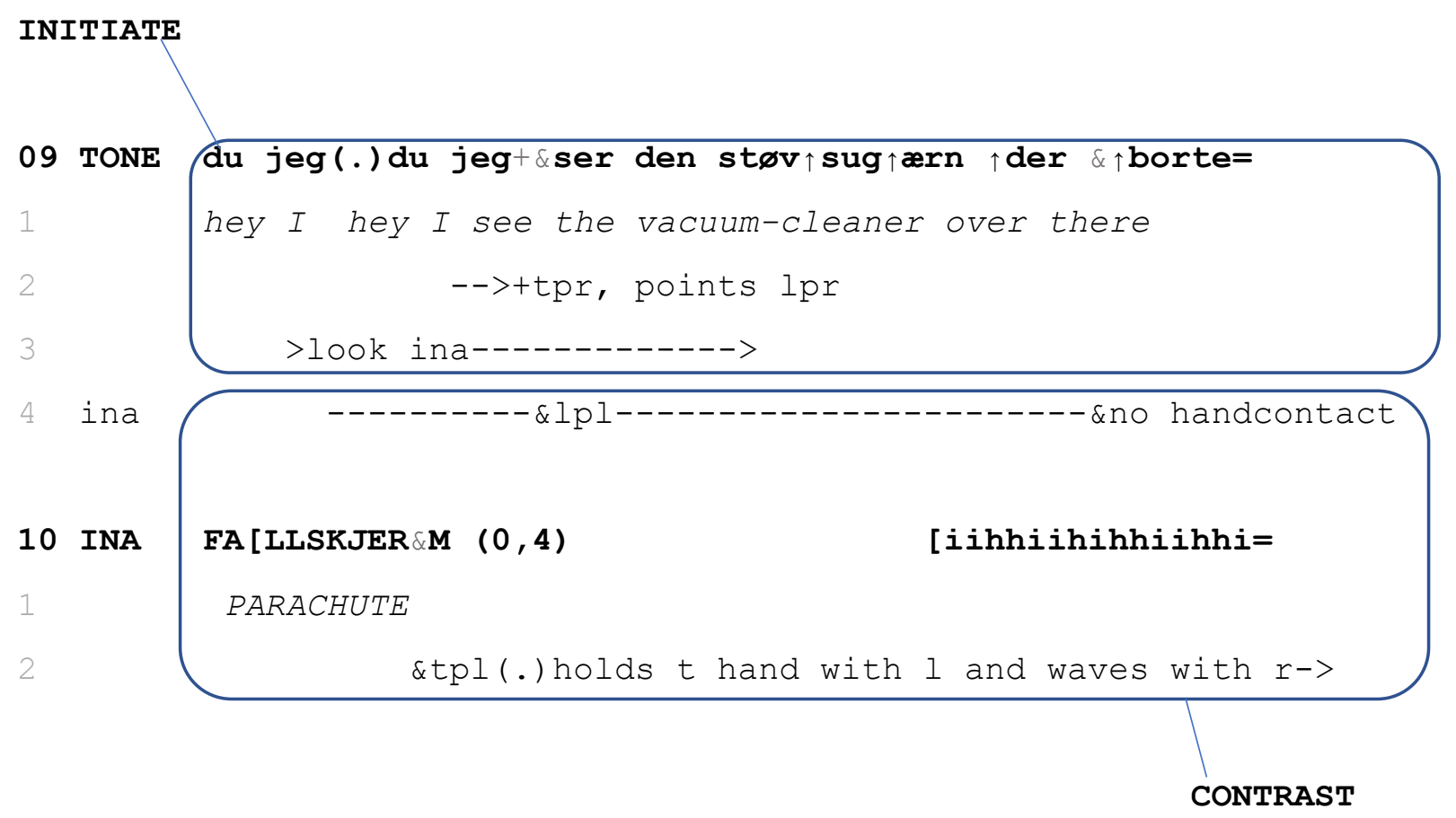

11 TONE

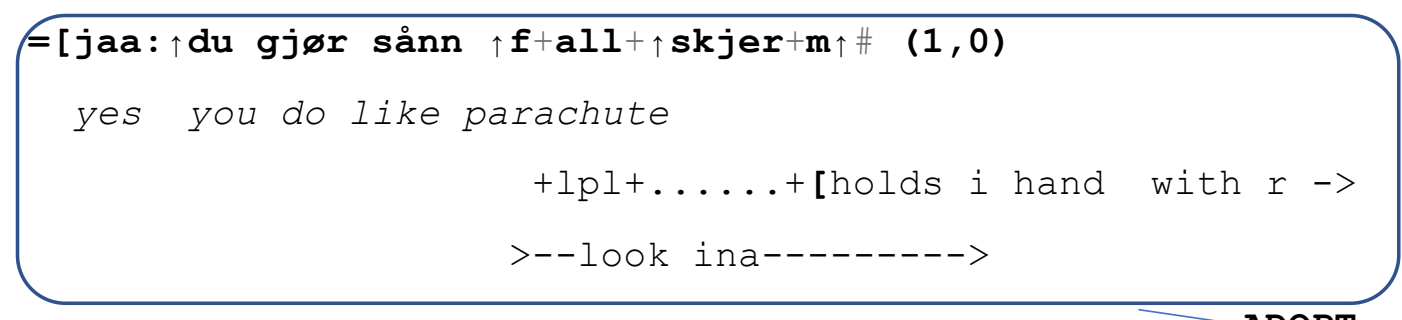

ADOPT

Just as in lines 9-11, in lines 12-14 there is a sequence of two successive acts of subjectivity, followed by one act of intersubjectivity. In line 15-16, however, this increases to a sequence of four successive acts of subjectivity followed by one act of intersubjectivity. This is again, immediately followed by a sequence of another four successive acts of subjectivity and then one act of intersubjectivity. Tension increases in the interaction, as both participants struggle to establish themselves as an agent that can impose her individual meaning on the communication.

Tension has risen in line 17 when Tone persists in her acts of subjectivity in while Ina replies with her own act of subjectivity $(17,4-17,6)$. Things are about to change however, as Ina is forced to stop. She continues to contrast Tone`s utterance by sticking to her song (part of her theme), but her other theme (movement in the opposite direction) is no longer possible. Her act of subjectivity has been weakened, though not completely abandoned. 
Extract 7

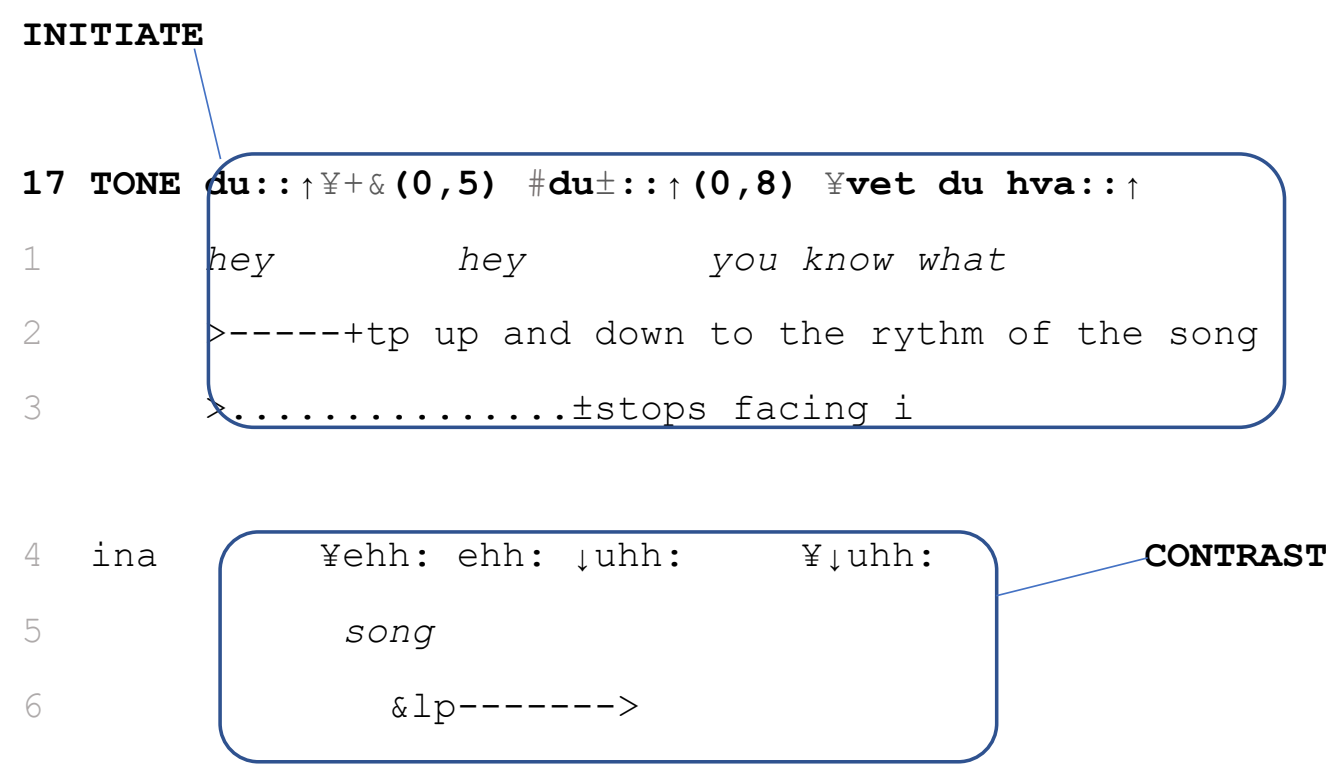

Tone, through another act of subjectivity, then utters a long vocal sentence (18) and at the same time starts walking back $(18,3)$, leading Ina by the hand $(18,2)$, and this seems to be the point at which Ina relinquishes her own project. She can no longer endure the tension that has arisen in their dialogue, and she gives in. By way of an act of intersubjectivity, she stops singing her melody $(18,4)$, turning and walking with Tone $(18,6)$.

In line 19 she retains part of her theme (the sign of Parachute), only she is now walking in Tone`s direction (towards the vacuum cleaner), not her own $(19,3)$. It is therefore possible to assume that the sign of Parachute now holds a new meaning for Ina based on the specific time and place of the utterance being changed. These utterances, in belonging to different times and spaces, then have the potential to hold different communicative meanings, but are all part of Ina`s desire to establish herself as an agent and thus to manifest her own self in the world. 
Extract 8
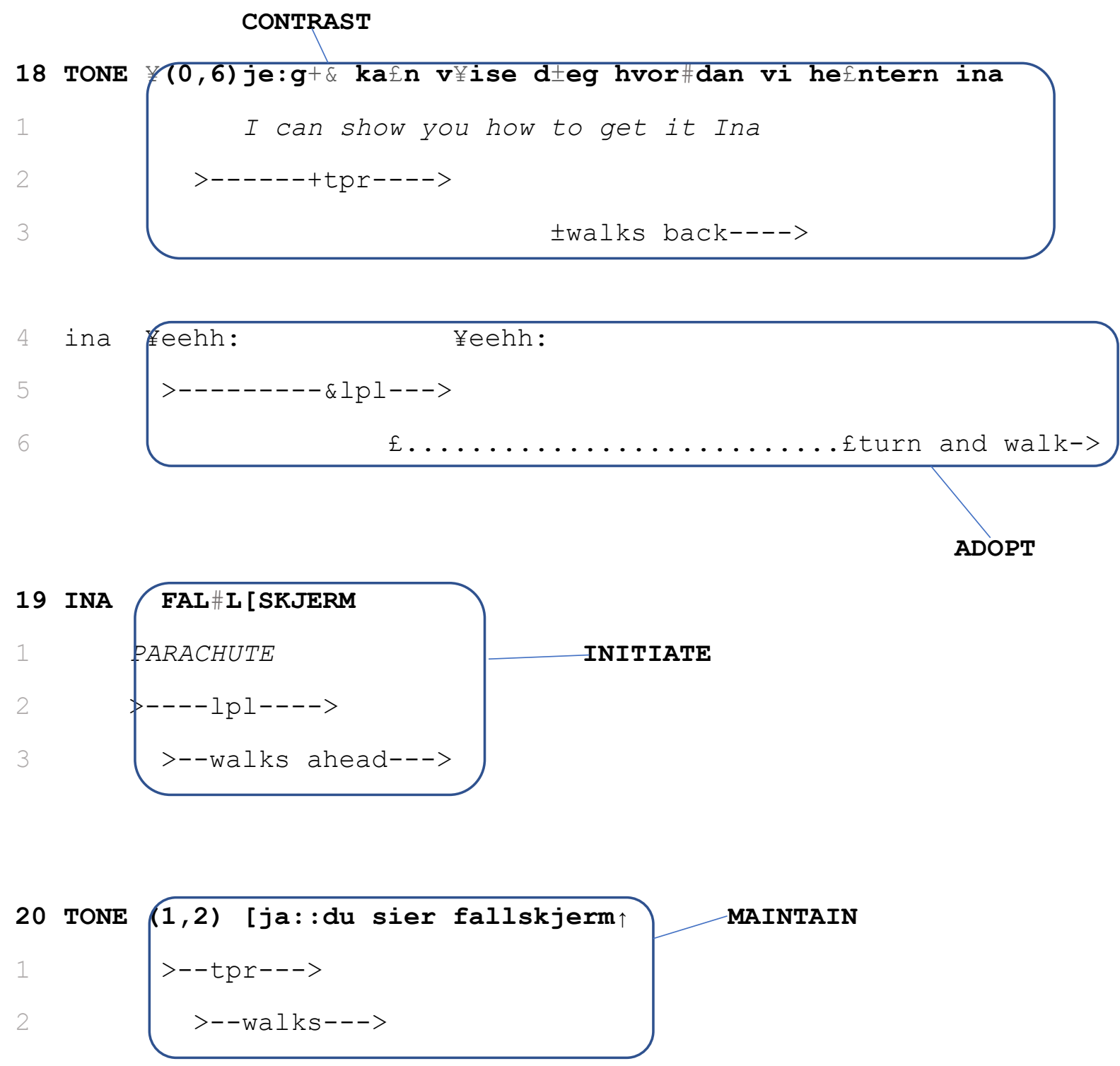

\section{Conclusion and discussion}

This research investigated if and to what extent improvisation can contribute to or support the development of communicative agency, especially for a person with CDB and with low readability and authentic language. The study was based on the assumption that there is a logical interconnection between improvisation, here seen through the model of improvisation developed by Wilson and MacDonald, and the understanding of communicative agency as an individual person`s opportunities and abilities to express her or his own subjective self in interaction with others. It can be stated that the connection between improvisation and communicative agency has been identified through the different analyses that have been performed. Communicative agency has been explored through the lenses of turn-taking, subjectivity/intersubjectivity and multimodality. The results of this study support 
the claim that improvisation contributed to specify subjectivity/intersubjectivity and multimodality in the interaction, though it did not contribute to specify turn-taking.

\section{Sub-questions}

To the first sub-question, the extent to which the improvisation model can contribute to the analysis of turn-taking patterns, it became quite clear that the model was not useful for this purpose. The improvisation model requires turns to be identified as turns before it can be applied. As a result, CA was selected as a better method for analysis of turn-taking patterns in the multimodal sequence of atypical communication. Turn-taking patterns in multimodal communication are complex, with many actions occurring simultaneously. This required basing the CA analysis on the transcript of the sequence to safeguard accuracy. CA revealed itself to be a very useful tool for analysis of turn-taking patterns, also because it is based on the idea that social actions occur sequentially in all interaction.

The second sub-question is to what extent the improvisation model can contribute to the analysis of the dialogical dynamics of subjectivity/intersubjectivity. The findings of this study show that through the improvisation model, it is possible to define each turn as either leaning towards subjectivity or towards intersubjectivity, and that in turn allows for the counting of acts of subjectivity/intersubjectivity by each participant throughout the sequence. It is not, however, only a matter of how many acts of subjectivity/intersubjectivity that can be identified in the sequence, but also in what order they appear, how balanced they are between the two participants and, maybe most importantly, how these acts are met by the other. The model of improvisation proved to be a valuable contribution to the analysis of the dialogical dynamics of subjectivity/intersubjectivity. This is very important because acts of subjectivity are essential for the development and sustainability of communicative agency, particularly for the person with $\mathrm{CDB}$ who communicates with atypical communication.

The third sub-question asks the extent to which the improvisation model can contribute to the analysis of different modalities in multimodal interaction. Findings suggest that the improvisation model can provide information about the dialogical intention of every turn from each participant of the dialogue, on a microlevel. This facilitates production of a very detailed and accurate transcript from which it is possible to observe the participants communicating different things through different modalities simultaneously. For example, it might easily appear to the casual viewer, that it is Tone`s vocal speech that acts as the driving force throughout this video. Rather, the analysis shows that the communicative action occurs entirely in the bodily tactile modality first, and then it is spoken. The effect is that of the same story being told twice in two modalities, with the oral auditive modality always behind the bodily tactile modality. Tactile utterances are replied to instantly in a highly competent flow 
between the two participants, whereas several spoken utterances are replied to much later in the dialogue, or in several examples, not replied to at all. Such results are significant for the development of communicative agency because they illustrate ways of making the low readability of expressions from persons with $\mathrm{CDB}$ more available to communication partners.

\section{Balance of subjectivity/intersubjectivity}

The model of improvisation can make interesting contributions to the analysis of communicative agency in atypical communication. By applying the model it is possible to identify every utterance as an active choice (Lewis, 1996), one that is central in the moment to shaping the dialogue into whatever it becomes. Each of these choices, or utterances, can provide information about where the person is located a) on the scale of expression of the self (subjectivity) and a co-created understanding with the other (intersubjectivity), and b) at the precise time and place, or chronotope (Bakhtin, 2010) in which the utterance is delivered. One can then look at each utterance sequentially, where each turn is viewed as being in a reflexive relationship with what came before and what comes next. In this way, the model of improvisation makes it possible to look at the balance of subjectivity/intersubjectivity between the participants in a dialogue.

The findings from the analysis show that acts of subjectivity in themselves do not threaten the balance and flow between the participants in the dialogue; on the contrary, they seem to be what drives the communication forward with new initiatives, thus upholding the dialogical tension (Bakhtin, 2010). Potential trouble occurs, however, when an act of subjectivity is met by another act of subjectivity, as they then oppose one another. This need not endanger the flow of the dialogue however, it can even make it more interesting, but the tension will increase because of the presence of two opposing wills engaged in a struggle for superiority in the dialogue (Nafstad, 2015). Acts of intersubjectivity will decrease the tension and keep the dialogue flowing (Linell, 2009, p. 81), but if these acts do not occur, and if several acts of subjectivity follow in a sequence tension may rise to a level that is difficult to endure, and one of the participants may have to give in for lack of alternative options (Nafstad, 2015). The ambiguity or open-endedness that is one of the qualities that must be present in improvisation (MacDonald \& Wilson, 2020) is no longer present, because the subjectivity of the most persistent participant in the dialogue will take over and leave no way out. Without ambiguity, or an open-ended outcome for each utterance, the communicative interaction is no longer improvisation, and the flow of dialogue is at risk of drying up.

\section{Multimodality}

The model of improvisation also has much to contribute to study of the multimodal aspects of the communication in the video, by treating each utterance in all modalities as an 
intentional choice made in a dialogical response to the other. This implies that every utterance is communicative and authentic, meaning they come from the thoughts of the speaker (von Tetzchner \& Jensen, 1999), and as such should be treated as having equal communicative value. In improvisation, any utterance is an intentional choice of communication with equal importance, whether it is a well-spoken sentence or a bodily tactile gesture (Foote, 2019; Nafstad \& Rødbroe, 2015; Souriau et al., 2009) with low readability. This is in line with the theory of Translanguaging (Otheguy, García, \& Reid, 2015), that treats a speaker`s full expressive repertoire as language, without letting cultural and political boundaries define what is formal language and what is not (Otheguy et al., 2015). We each have a unique way of expressing meaning using the different modalities that are at hand and neither translanguaging nor improvisation make any distinction between modalities or whether the utterance is made in a formal language or not. This perspective supports acknowledgement of communicative agency for persons with authentic language and low readability.

\section{CA}

In this study CA has been used as a framework for transcribing the video and for the sequential analysis of the transcript, and is a useful research methodology for the systematic gathering, transcribing and analysing of social interaction (Skovholt et al., 2021). CA has indeed proven itself useful for the study, especially in the sequential analysis of the transcript, because it enables the identification of all the different actions, whether these appear in turn, out of turn or simultaneously in a complex multimodal interaction between a person with $\mathrm{CDB}$ and a sighted/hearing communication partner. Most of the findings in this study were derived through analysis of the high-precision transcript, with special attention to the aspects of time and sequentiality. Without the introduction of the model of improvisation, however, this focus would not have developed because of lack of a clear analysis of the basic dynamic structure of the interaction.

CA is preoccupied with describing sequentiality in terms of utterances sorted into adjacencypairs or expansions of adjacency-pairs, something that may not be as universal and fundamental as theorists of CA claim (Linell, 2009, p. 186). Alternatively, improvisation theory opens the analysis by bringing the possibilities for every utterance or action in the dialogue into focus. Treating utterances as choices also implies that all actions and utterances potentially have a multitude of different outcomes. Every utterance can be replied to in any number of ways, depending on both exterior and interior factors, time and place being especially important. Every moment holds the possibility for change, and the dialogical concept of multivoicedness, or polyvocality, meaning that every utterance contains elements of other texts or utterances (Linell, 2009, p. 246), increases when including not yet realised aspects of meaning. This recognition that every moment in time and space has infinite possibilities, and further that there is always transformative potential in every action we 
perform, are important pedagogical principles supported by improvisation. As Bakthin says, "Nothing conclusive has yet taken place in the world, the world is open and free, everything is still in the future and will always be in the future" (M. Bakhtin, 2013).

\section{Limitations}

This study has limitations, the first one being that the analysis and the transcript were constructed and performed by the researcher alone. When analysing videos, the circulation of ideas does not only refer to the interaction in the video itself, but also to the knowledge and prior experience of the analysist (Marková, Linell, Grossen, \& Salazar Orvig, 2007). Therefore, the analysis has potential to be richer when several people work together as analysts, as in focus groups where everyone in the network of the person with CDB participates (Nafstad \& Rødbroe, 2015). A second limitation that also could be remedied through analysis in focus groups, was that the researcher did not know the participants very well, particularly not the person with CDB. Her signs, expressions, songs, and life experiences, as well as those of the communication partner were not well known by the researcher. A third limitation in this study was that only one sequence featuring a person with $\mathrm{CDB}$ and a sighted/hearing communication partner was analysed. More sequences with the same, or different persons could provide us with a better base for further analysis. Future research should be conducted in which analysis is performed in focus groups with participants informed about the theories of both improvisation and communicative agency. A higher number of videos could also be considered to improve reliability of the results would be higher (Flick, 2018).

\section{Implications for practice}

There are some important implications for practice in this study. It can be useful for support workers to be aware of the dynamics of subjectivity/intersubjectivity in dialogue with person with $\mathrm{CDB}$ or any type of atypical communication. Knowing about these dynamics, with special attention to the balance that should be maintained in the dialogue, between utterances leaning towards subjectivity and utterances leaning towards intersubjectivity, is important for both the participants and for the dialogue itself. If one of the participants, most often the sighted/hearing partner, dominates the dialogue with subjectivity the dialogue will end, and the person with atypical communication will not have improved her/his communicative agency. Improvisation can be a useful way of thinking about this in everyday life, by directing attention to the flow of the dialogue, facilitate avoidance of too many contrasting utterances and most importantly, improve awareness of the importance of the ambiguity or open-endedness of all utterances. Reduction of possible interpretations of an utterance to a single meaning in a dialogue ends improvisation. Having this in mind, this study can be used as an exemplary case study for people with low readability and authentic language. Another interesting implication for practice in this study is the finding that all the 
important communication between the two persons in the video occurred first in the bodily tactile modality and then in the oral auditive modality. This is important to consider, especially in communication with persons with CDB who have residual hearing and/or vision. It is so easy for sighted/hearing persons to relate to the senses that are best known to them, and thereby expect the person with CDB to perceive the world as they do. The knowledge that the bodily tactile modality is the primary window into the world for most people with CDB should have significant implications for practice for support workers.

\section{Further research}

This study identified several interesting points of departure for further research. More research into the sequential relation between expressions in the bodily-tactile modality and the oral auditive modality is recommended. Findings in this study support that communication through bodily-tactile modality occurs before communication in the oral auditive modality and this is in line with what McNeill (2011) says about conventional speech unfolding from spontaneous gestures. More extensive research into the field of improvisation and atypical communication is recommended as well to expand knowledge of the liberating and agency-enhancing aspects of improvisation so vital for persons with atypical communication, authentic language, and low readability. Further research into the interconnection of dialogical theory and CA is also recommended, to develop better insight into how, and to what extent they are compatible with one another.

\section{References}

Anglin, J. M. (1977). Word, object, and conceptual development: WW Norton.

Bailey, D. (1992). Improvisation : its nature and practice in music ([2nd ed.]. ed.). London: The British Library, National Sound Archive.

Bakhtin. (2010). The dialogic imagination: Four essays (Vol. 1): University of texas Press.

Bakhtin, M. (2013). Problems of Dostoevsky's poetics (Vol. 8): U of Minnesota Press.

Brinkmann, S. (2015). Etik i en kvalitativ verden. In Kvalitative metoder: En grundbog (pp. 463-479): Hans Reitzels Forlag.

Broth, M., \& Keevallik, L. (2020). Multimodal interaktionsanalys: Studentlitteratur AB.

Cambridge. Improvisation. In Cambridge Dictionary.

Davidsen, J., \& Kjær, M. (2018). Videoanalyse af social interaktion. København: Samfundslitteratur.

Due, B. L. (2017). Multimodal interaktionsanalyse (Vol. nr. 4). Frederiksberg: Samfundslitteratur.

Flick, U. (2018). An introduction to qualitative research: Sage. 
Flick, U. (2020). Introducing Research Methodology: Thinking Your Way Through Your Research Project: Sage.

Foote, C. (2019). Languaging between a child with congenital deafblindness and a bimodal, bilingual teacher. In If you can see it, you can support it (pp. 69-81): Nordic Welfare Centre.

Janssen, H. J. M., \& Rǿdbroe, L. (2007). Communication and congenital deafblindness: Contact and social interaction: VCDB/Viataal.

Jefferson, G. (1984). On stepwise transition from talk about a trouble to inappropriately nextpositioned matters. Structures of social action: Studies in conversation analysis, 191, 222.

Jefferson, G. (2004). Glossary of transcript symbols. Conversation analysis: Studies from the first generation. Amsterdam: John Benjamins, 13-31.

Johnstone, K. (2012). Impro: Improvisation and the theatre: Routledge.

Kitzinger, C. (2012). Repair. In The handbook of conversation analysis (pp. 229-256): Wiley Blackwell.

Kvifte, T. (2013). Improvisasjon i folkemusikk-tradisjon, nyskaping eller påvirkning. Musikk og tradisjon, 27(2013), 47-60.

Lewis, G. E. (1996). Improvised music after 1950: Afrological and Eurological perspectives. Black music research journal, 91-122.

Lie, H. (2021). Improvisation and communicative agency. (Master), University of Groningen, Linell, P. (2009). Rethinking language, mind, and world dialogically : interactional and contextual theories of human sense-making. Charlotte, N.C: Information Age Publ.

MacDonald, R. A., \& Wilson, G. B. (2020). The Art of Becoming: How Group Improvisation Works: Oxford University Press.

Mandelbaum, J. (2013). 24 Storytelling in Conversation. In The handbook of conversation analysis (pp. 492): Wiley Blackwell.

Markova, I. (2008). Dialogicality. Paper presented at the Deafblind International Conference 2008.

Markova, I. (2017). Case studies and dialogicality. Journal of Deafblind studies on Communication, 3(1), 28-45.

Marková, I. (2006). On 'the inner alter' in dialogue. International Journal for Dialogical Science, 1(1), 125-147.

Marková, I. (2016). The Dialogical Mind Common Sense and Ethics. Cambridge : UK ;: Cambridge University Press.

Marková, I., Linell, P., Grossen, M., \& Salazar Orvig, A. (2007). Dialogue in focus groups: Exploring socially shared knowledge: Equinox publishing.

Marková, I., Zadeh, S., \& Zittoun, T. (2020). Introduction to the special issue on generalisation from dialogical single case studies. Culture \& Psychology, 26(1), 3-24. 
McNeill, D. (2011). Hand and mind: De Gruyter Mouton.

Moltubak, J. (2020). Improvisasjon i klasserommet : frigjør superkraften. Oslo: Universitetsforlaget.

Mondada, L. (2007). Multimodal resources for turn-taking: Pointing and the emergence of possible next speakers. Discourse studies, 9(2), 194-225.

Mondada, L. (2013). The conversation analytic approach to data collection. In The handbook of conversation analysis (pp. 32-56): Wiley Blackwell.

Mondada, L. (2018). Multiple temporalities of language and body in interaction: Challenges for transcribing multimodality. Research on Language and Social Interaction, 51(1), 85-106.

Morgan, M. S. (2012). Case studies: One observation or many? Justification or discovery? Philosophy of Science, 79(5), 667-677.

Nachmanovitch, S. (1990). Free play: Improvisation in life and art: Penguin.

Nafstad. (2015). Communication as cure. Communicative agency in persons with congenital deafblindness. Journal of Deafblind studies on Communication, 1(1), 23-39.

Nafstad, \& Rødbroe. (2015). Communicative relations. Interventions that create communication with persons with congenital deafblindness. In: Aalborg: Materialecentret.

Nordic definition of Deafblindness. $(2016,2016)$. Retrieved from https://nordicwelfare.org/wp-content/uploads/2018/03/nordic-definition-ofdeafblindness.pdf

Otheguy, R., García, O., \& Reid, W. (2015). Clarifying translanguaging and deconstructing named languages: A perspective from linguistics. Applied Linguistics Review, 6(3), 281-307.

Peräkylä, A. (2011). Validity in research on naturally occurring social interaction. Qualitative research, 365, 382.

Rescorla, L. A. (1980). Overextension in early language development. Journal of child language, 7(2), 321-335.

Robson, C., \& McCartan, K. (2016). Real world research: John Wiley \& Sons.

Sacks, H. (1966). The search for help: No one to turn to: University of California, Berkeley.

Schegloff, E. A. (2007). Sequence organization in interaction: A primer in conversation analysis I (Vol. 1): Cambridge university press.

Sidnell, J. (2013). Basic conversation analytic methods. In The handbook of conversation analysis (Vol. 77, pp. 99): Wiley Blackwell.

Skovholt, K., Landmark, A. M. D., Sikveland, R. O., Solem, M. S., \& Skovholt, K. (2021). Samtaleanalyse : en praktisk innføring (1. utgave. ed.). Oslo: Cappelen Damm akademisk. 
Souriau, J., Rødbroe, I., \& Janssen, H. J. M. (2009). Transition to cultural language: Communication and congenital deafblindness. Handbook 4 (with cd-rom): VCDB/Viataal.

Steinsholt, K., \& Sommerro, H. (2006). Improvisasjon: kunsten å sette seg selv på spill: Damm. Stivers, T. (2013). 10 Sequence Organization. In The handbook of conversation analysis (pp. 191): Wiley Blackwell.

von Tetzchner, S., \& Jensen, K. (1999). Interacting with people who have severe communication problems: Ethical considerations. International Journal of Disability, Development and Education, 46(4), 453-462.

Wikipedia. Improvisation. In Wikipedia, The Free Encyclopedia.

Wilkinson, R., Rae, J. P., \& Rasmussen, G. (2020). Atypical Interaction: Springer.

Wilson, G. B., \& MacDonald, R. A. (2016). Musical choices during group free improvisation: A qualitative psychological investigation. Psychology of Music, 44(5), 1029-1043.

\section{Acknowledgements}

We would like to acknowledge language-advisor Kirsten Costain for a thorough and invaluable review of the paper. We would like to acknowledge the participants of this study and STATPED, Oslo, Norway for the support.

Håkon Lie, Senior Advisor, STATPED, Unit for Dual Visual and Hearing Loss and Deafblindness, Oslo, Norway

Anne V. Nafstad, Psychologist, Department of Deafblindness and Combined Visual and Hearing Impairment STATPED Southeast, Oslo, Norway, Former Lecturer, Inclusive and Special Needs Education. University of Groningen, Netherlands 